\title{
II The relationship between metabolites and the progress of the disease studied in outpatients
}

SUMMARY Serum concentrations of salicylazosulphapyridine (SASP), sulphapyridine (SP), and 5-aminosalicylic acid (5-ASA) were measured in 64 outpatients with ulcerative colitis. About $90 \%$ of the patients in remission had serum total SP concentrations above $20 \mu \mathrm{g} / \mathrm{ml}$. Seven patients, however, had active disease despite a serum total SP concentration $>20 \mu \mathrm{g} / \mathrm{ml}$. The SASP and the individual SP metabolites did not show any correlation with the disease state. Three g per day seems to be the most effective dose. Plain and enteric-coated tablets produced similar concentrations at equivalent dosage. Side effects due to SASP were frequent in patients who had a total SP concentration $>50 \mu \mathrm{g} / \mathrm{ml}$ of serum.

The present study was carried out to determine (1) the serum concentration of SASP and its metabolites in patients on long-term therapy; (2) whether there is any correlation between the serum concentration of SASP or its metabolites with the clinical state of the patients; (3) the most effective dose for long-term therapy; and (4) if the relationship between the serum concentration of the drug and its metabolites and the disease state varied with plain and enteric-coated tablets.

\section{Patients, Materials, and Methods}

Sixty-four patients with ulcerative colitis were studied while they were attending the follow-up clinic. The clinical state of the disease was judged on the basis of symptoms and sigmoidoscopic appearances. The attending physician completed a proforma for each patient stating age, sex, details of the disease, activity, extent, present dose of SASP, duration of therapy, type of tablets (plain or enteric-coated), time of last dose taken, time of collection of blood, and the presence of any side effects. Of the 64 patients, 41 were in remission, 21 had mild to moderate activity, and two had severe activity (Jalan, Prescott, Sircus, Card, McManus, Falconer, Small, Smith, and Bruce, 1971). No distinction was made between mild and moderate cases. Salicylazosulphapyridine had been prescribed for six months to 15 years. In addition six patients were also under treatment with steroid retention enemata and 11 other patients were receiving enemata plus oral corticosteroids, ie, prednisolone (three patients, $10-40 \mathrm{mg} /$ day), or corticotrophin preparations (Synacthen in eight patients, $0.25 \mathrm{mg}-0.5 \mathrm{mg}$ twice a week). Five of the eight patients receiving Synacthen injections were taking immunosuppressives (Azathioprin 1-2 mg/kg of body weight). Those patients who were treated with corticosteroids were also taking potassium supplements and Nystatin. Other drugs used were iron, codeine phosphate, diazepam, and nitrazepam. Blood samples were obtained from all these patients over a period of one year. Twenty patients had multiple collections. Simultaneously, a sample of blood was always sent for haematological examination and for liver function tests.

\section{Analysis of serum}

Each serum sample was analysed for sulphasalazine (SASP), free sulphapyridine (SP), $\mathrm{N}^{4}$-acetyl sulphapyridine (ACSP), sulphapyridine-o-glucuronide (SP-Gluc), and $\mathrm{N}^{4}$-acetyl-sulphapyridine-o-glucuronide (ACSP-Gluc) (Sandberg and Hansson, 1973; Hansson and Sandberg, 1973). Serum samples from 25 different patients were estimated for 5-amino salicylic acid (5-ASA) by spectrofluorometry (Hansson, 1973). Steroids, nitrazepam, and diazepam had no effect on the methods.

\section{Results}

Table I shows the serum concentration of SASP and its metabolites in patients with active disease or in remission. Serum SASP concentrations did not show any significant difference between these two groups of patients with mean concentrations of 15.6 and $12.1 \mu \mathrm{g} / \mathrm{ml}$ respectively. However, a significant difference was noted between the serum concentration of both free and total SP. $\mathrm{N}^{4}$-acetyl sulphapyridine did not differ significantly but free SP and ACSP together showed significant differences. The serum glucuronide concentrations, ie, SP-Gluc and ACSP-Gluc, were low both in the active and remission phases of the disease and there was no significant difference between SP-glucuronides in the two groups.

Serum concentrations of the 5-ASA component of SASP were found to be very low $(0-2 \cdot 8 \mu \mathrm{g} / \mathrm{ml}$, $0.8 \pm 0.6$ ) irrespective of the disease state. 


\begin{tabular}{|c|c|c|c|}
\hline & \multicolumn{2}{|c|}{$\begin{array}{l}\text { Serum Concentration } \\
(\mu g / m l)(\text { mean } \pm S D)\end{array}$} & \multirow[t]{2}{*}{$\begin{array}{l}\text { Statistical } \\
\text { Significance }\end{array}$} \\
\hline & $\begin{array}{l}\text { Patients with } \\
\text { Activity }(n=23)\end{array}$ & $\begin{array}{l}\text { Patients in } \\
\text { Remission }(n=41)\end{array}$ & \\
\hline $\begin{array}{l}\text { SASP } \\
\text { Free SP } \\
\text { ACSP } \\
\text { SP-Gluc } \\
\text { ACSP-Gluc } \\
\text { SP + ACSP } \\
\text { Total SP } \\
\text { 5-ASA }\end{array}$ & $\begin{array}{c}15.6 \pm 15 \\
9.8 \pm 6.1 \\
6.8 \pm 4.8 \\
1.2 \pm 1 \\
1.6 \pm 1.9 \\
16.7 \pm 9.2 \\
18.1 \pm 10.5 \\
0.6 \pm 0.4\end{array}$ & $\begin{array}{r}12.1 \pm 11.6 \\
16.9 \pm 8.7 \\
8.6 \pm 6.6 \\
1.8 \pm 1.6 \\
3.0 \pm 2.2 \\
26.0 \pm 9.9 \\
30.8 \pm 9.7 \\
0.9 \pm 0.7\end{array}$ & $\begin{array}{l}\text { NS } \\
\mathrm{P}<0.001 \\
\mathrm{NS} \\
\mathrm{NS} \\
\mathrm{P}<0.05 \\
\mathrm{P}<0.001 \\
\mathrm{P}<0.001 \\
\mathrm{NS}\end{array}$ \\
\hline
\end{tabular}

Table I Serum concentration (mean $\pm 1 S D$ ) of sulphasalazine and its metabolites in active and remission state of the disease

'Estimated in 25 patients, 10 active and 15 in remission

NS $=$ not significant

The results for acetylation polymorphism using sulphapyridine were found to parallel those for sulphadimidine. In the steady state situation in patients on SASP therapy the acetylation ability was found to be constant (Das and Eastwood, 1973). Of the 64 patients studied, 45 were slow acetylators and 19 were fast acetylators.

Figure 1 compares the serum concentration of total SP in patients, subdividing the groups into slow or fast acetylators and also according to whether the disease was active or in remission. All but three of the 50 samples of serum taken in remission had total SP concentrations above $20 \mu \mathrm{g} / \mathrm{ml}$, but 23 of the 30 patients examined during an active phase of colitis had serum total SP concentrations below $20 \mu \mathrm{g} / \mathrm{ml}$ and seven others (four slow acetylators and three fast acetylators) were in an active phase despite total serum SP concentration above $20 \mu \mathrm{g} / \mathrm{ml}$. Of these seven patients, two had had recent relapses following which the dose of SASP had been increased; four other patients were also on azathioprin and steroids. If the serum concentration of SASP or of each of the individual metabolites of SP were graphed in a similar way to fig 1, no clear distinction would exist between the serum concentration and disease state.

In slow acetylators most of the total serum sulphapyridine was in the free form, whereas in the fast acetylators acetyl-sulphapyridine predominated. The SP-glucuronides had a low concentration both in fast and slow acetylators in the active and remission states (table II). Table II shows that when individual metabolites were analysed for patients in the active or remission state of the disease only the total SP concentration was significantly different in the two groups, irrespective of the acetylator phenotype. Table III shows the serum concentration of SASP and total SP with different dose schedules. There was no difference in SASP concentration at any dosage in the range of 2 to $4 \mathrm{~g} /$ day. However, the

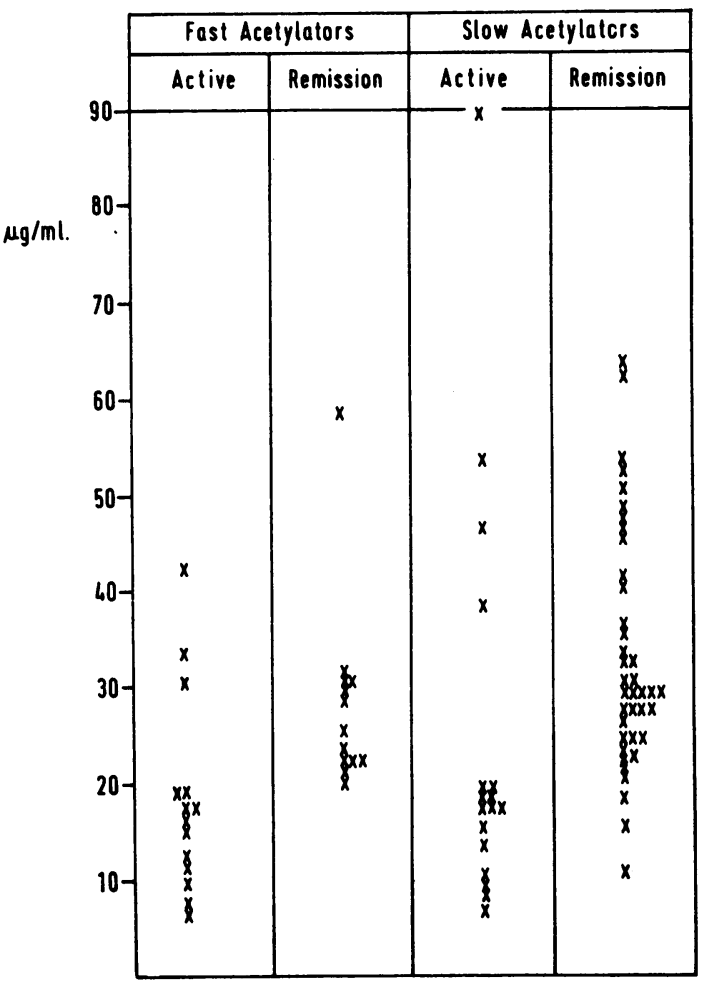

Fig 1 Serum concentration of total sulphapyridine in slow and fast acetylators during active and remission states of ulcerative colitis

serum total SP became progressively higher with increasing dosage and this was more evident in slow acetylators compared with fast acetylators on the same dosage. Although the serum concentration of total SP could be correlated with the dosage of SASP 


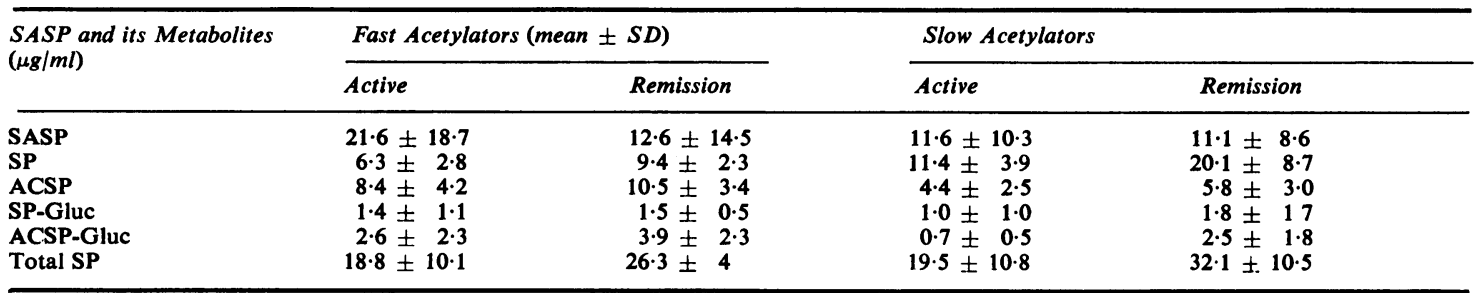

Table II Sulphasalazine (SASP) and its sulphapyridine metabolites in outpatients with ulcerative colitis in active state and in remission for slow and fast acetylators

\begin{tabular}{lccc}
\hline $\begin{array}{l}\text { Dose of Sulphasalazine } \\
(\mathrm{g} / \text { day })\end{array}$ & $\begin{array}{l}\text { No. of Patients at } \\
\text { First Examination }\end{array}$ & \multicolumn{2}{c}{ Mean $( \pm S D)$ Serum Conrentrations $(\mu g / m l)$} \\
\cline { 2 - 4 } & & Sulphasalazine & Total SP \\
\hline 2 & 3 & $9 \cdot 4 \pm 1 \cdot 1$ & $9 \cdot 8 \pm 2 \cdot 9$ \\
2 & 27 & $14 \cdot 1 \pm 14 \cdot 6$ & $22 \cdot 3 \pm 10 \cdot 5$ \\
3 & 19 & $11 \cdot 2 \pm 11$ & $30 \cdot 4 \pm 10 \cdot 8$ \\
4 & 12 & $14 \cdot 8 \pm 10 \cdot 7$ & $37 \cdot 1 \pm 12 \cdot 7$ \\
$>4$ & 3 & $23 \cdot 1 \pm 23 \cdot 5$ & $69 \cdot 7 \pm 28 \cdot 5$ \\
\hline
\end{tabular}

Table III Serum concentration of sulphasalazine and total sulphapyridine in 64 outpatients in relation to dosage of sulphasalazine

in terms of grams per day this did not appear to be a function of body weight ( $\mathrm{mg} / \mathrm{kg}$ body weight).

In fig 2 the serum total SP concentration is related to different doses of SASP in patients in activity and in remission. Forty-five per cent of the patients taking $2 \mathrm{~g}$ of SASP per day had active colitis and their serum total SP was $<20 \mu \mathrm{g} / \mathrm{ml}$, whereas most of the patients taking $3 \mathrm{~g}$ or more SASP per day were in remission and they had a serum total SP concentration above $20 \mu \mathrm{g} / \mathrm{ml}$.

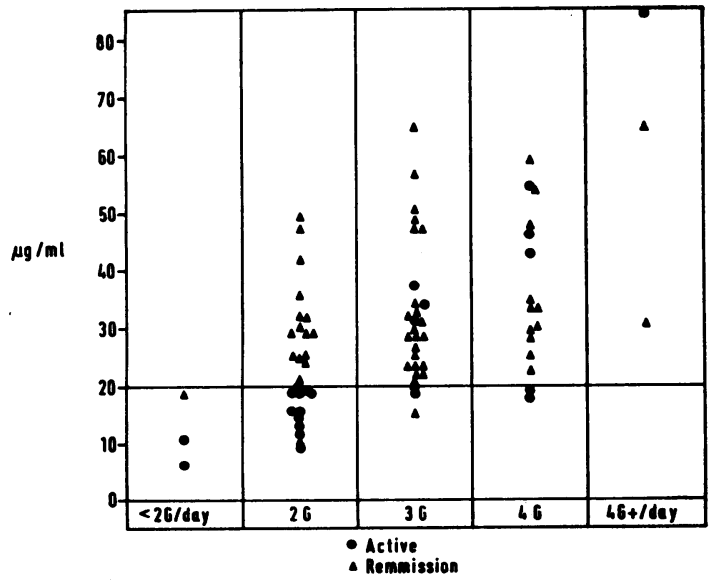

Fig 2 Serum concentration of total sulphapyridine in relation to dosage of sulphasalazine (g/day) and the clinical states of the disease
Seven patients, however, showed active colitis despite a serum total SP concentration $>20 \mu \mathrm{g} / \mathrm{ml}$. Of the eight patients who had side effects, eg, blue discoloration of serum and mucosa (4), transient reticulocytosis (3), and haemolysis (1), six of them were taking $4 \mathrm{~g}$ or more and two were taking $3 \mathrm{~g}$ of SASP per day. Of the 64 patients studied, 21 were taking enteric-coated tablets and the rest were on plain tablets. Of these 21 , seven were in the active stage of the disease.

The serum concentration of SASP was slightly lower in patients taking enteric-coated tablets $(11 \mu \mathrm{g} / \mathrm{ml} \pm 11.5)$ as opposed to the patients who were on plain tablets $(16.5 \mu \mathrm{g} / \mathrm{ml} \pm 13.9)$. The serum concentration of individual metabolites of SP and of total SP did not differ between patients on plain or enteric-coated tablets at the same dosage. Liver function test results remained normal throughout.

\section{Discussion}

We have reported the metabolism of sulphasalazine in patients with active ulcerative colitis during the introduction of therapy with this agent and during follow up of these patients for up to one year in part I. To evaluate any relationship between the disease serum total SP concentration above $20 \mu \mathrm{g} / \mathrm{ml}$. state and serum concentration of the drug or its metabolites it was necessary to study a larger group of patients taking SASP for longer periods of time and in different phases of the disease. This is of 
clinical relevance as it was shown that SASP has a significant role in the prevention of relapses (Misiewicz et al, 1965). We have shown that the serum SASP concentration has a very wide range both in active and remission stages of the disease and there was no correlation between serum concentration and the disease state. The wide range of SASP concentration was also reported in healthy volunteers (Schröder and Campbell, 1972). It was suggested that this wide variation between individuals was probably related to differences in absorption, and there may be a further contributory factor to explain this wide range. Sulphasalazine has a short half life (three to five hours), therefore the timing of the last dose before collection of blood sample will be relevant and will influence its serum concentration. Many of our patients were taking the tablet twice a day, ie, in the morning (7-9 am) and at night $(6-10 \mathrm{pm})$. Collection at the outpatient clinic was between 2 and 5 p.m.

Most of the SASP is split in the colon by gut flora and the SP thus liberated is absorbed (Peppercorn and Goldman, 1972; Das, 1973) with a resultant serum total SP concentration. A low serum total SP concentration was consistently found during our earlier study in patients with active disease. It is difficult to say whether absorption improves with healing or whether higher serum concentrations of SP cause healing. It is possible that acute diarrhoea or any change in colonic bacterial flora, eg, after antibiotics, could reduce the splitting of SASP in the colon with less SP available for absorption. It has, however, been demonstrated that significant absorption of SP can occur in patients with active colitis (Das, Eastwood, McManus, and Sircus, 1973). Free SP is acetylated in the liver and the amount of ACSP thus formed is dependent on the acetylator phenotype of the person. It was found that only the serum total SP concentration differed significantly between the active and remission state of slow and fast acetylators. The majority of patients $(70 \%)$ are slow acetylators and most of the total SP in slow acetylators is free sulphapyridine. Fast acetylators had more ACSP in the serum than free SP irrespective of the clinical stage of the disease. It is possible that SP may have some therapeutic effect in the treatment of colitis (Svartz, 1942). There is no study reported where ulcerative colitis has been treated with SP alone though studies with absorbable and poorly absorbed sulphonamides are available (Angelo, 1945; Trier, 1948; Moertel and Bargen, 1959). Sulphapyridine is also hydroxylated in the liver followed by conjugation with glucuronic acid. As SP glucuronides are polar metabolites their excretion is rapid and hence serum concentrations are relatively low. The serum concen- tration in both active and remission states were quite low and did not show any significant difference from the disease state.

The serum concentration of 5-ASA in the serum of 25 patients with active colitis or in remission was found to be very low $(0-2 \cdot 8 \mu \mathrm{g} / \mathrm{ml}$ with a mean of $0 \cdot 8 \pm 0.06)$. The serum concentration of 5-ASA was also found to be similar $(2 \mu \mathrm{g} / \mathrm{ml})$ in healthy persons. No significant correlation could be found with the disease state and serum concentrations of 5-ASA. 5 -ASA was found in the serum mostly ( $>80 \%$ ) in the free form and very little as acetylated 5-aminosalicylic acid.

Our results provide some guidance for the dosage of SASP to be used in the long-term management of ulcerative colitis. It may be relevant that the majority of patients with active disease were taking $2 \mathrm{~g}$ or less SASP per day, whereas the majority of patients in remission were taking $3 \mathrm{~g}$ or more. Neither dosage nor activity of the disease caused mild alteration in serum concentration of SASP though these factors did cause significant variation in total SP concentration.

Seven patients had active colitis despite a serum concentration of total SP of $>20 \mu \mathrm{g} / \mathrm{ml}$. They were on corticosteroids and in three instances were receiving immunosuppressive therapy. The severity of the disease in this group is underlined by the fact that three of these patients have subsequently undergone colectomy. Five out of seven of our patients with side effects were receiving a daily dose of $4 \mathrm{~g}$ or more of SASP and two (both slow acetylators) were taking $3 \mathrm{~g} \mathrm{SASP} /$ day. All the patients with side effects had a higher serum total SP than patients without side effects (Das, Eastwood, McManus, and Sircus, 1972b).

It thus seems that though $3 \mathrm{~g} /$ day is the optimum maintenance dose for slow acetylators, $2 \mathrm{~g}$ /day may be adequate. About a third of the patients treated with enteric-coated tablets were in the active state. The only difference in effect observed between plain and enteric-coated tablets was a slightly lower serum concentration of SASP with the latter, though this did not apply to SP metabolites. This is further supporting evidence for some absorption of the parent SASP from the small intestine and the predominantly colonic absorption of sulphapyridine. The contents of the enteric-coated tablets are probably not absorbed as efficiently as those of the plain tablets, but once SASP reaches the colon it is split and the type of tablet does not make much difference to the subsequent metabolism or the therapeutic effects of the drug. These results from the patients on long-term therapy confirm the observations made during the metabolic studies of SASP in initial attacks of active ulcerative colitis. A serum total SP 
concentration of 20 to $50 \mu \mathrm{g} / \mathrm{ml}$ correlated significantly with clinical remission, in the absence of side effects related to salicylazosulphapyridine, which itself, and other individual metabolites, showed no such correlation. It is possible that SASP carries the active metabolites to the site of inflammation and the therapeutic effect may occur during the phase of colonic absorption of the split metabolites, sulphapyridine or 5-aminosalicylic acid.

We wish to thank Pharmacia, Great Britain Limited for financing this work. We also wish to thank Mrs Ann Lane for secretarial assistance.

\section{References}

Angelo, G. (1965). Phthalylsulfathiazole-sulfathalidine: a clinical evaluation in 122 patients with proctologic and related conditions. Amer. J. Surg., 70, 354-359.

Baron, J. H., Connell, A. M., Lennard-Jones, J. E., and Jones, F. A. (1962). Sulphasalazine and salicylazosulphadimidine in ulcerative colitis. Lancet, 1, 1094-1096.

Das, K. M. (1973). From PhD Thesis 'Salicylazosulphapyridine metabolism in clinical practice', University of Edinburgh, 1973.

Das, K. M., Eastwood, M. A., McManus, J. P. A., and Sircus, W. (1972a). Salazopyrin metabolism in ulcerative colitis. (Abstr.) Gut, 13, 840.

Das, K. M., Eastwood, M. A., McManus, J. P. A., and Sircus, W. (1972b). Acetylator phenotype and adverse effects of salicylazosulphapyridine in patients with inflammatory bowel disease, (abstr). Scot. med. J., 17, 377-378.
Das, K. M., Eastwood, M. A., McManus, J. P. A., and Sircus, W. (1973). The metabolism of salicylazosulphapyridine in ulcerative colitis. I. The relationship between metabolites and the response to treatment in inpatients. Gut, 14, 631-636.

Hansson, K. A. (1973). Determination of free and acetylated 5-amino salicylic acid in serum and urine after administration of salicylazosulphapyridine. Acta pharm. suec., 10, 153.

Hansson, K. A., and Sandberg, M. (1973). Determination of sulfapyridine and its metabolites in biological materials after administration of salicylazosulphapyridine. Acta pharm. suec., 10, 87-92.

Jalan, K. N., Prescott, R. J., Sircus, W., Card, W. I., McManus, J. P. A., Falconer, C. W. A., Small, W. P., Smith, A. N., and Bruce, J. (1971). Ulcerative colitis, a clinical study of 399 patients. J. Roy. Coll. Surg. Edin., 16, 338-355.

Misiewicz, J. J., Lennard-Jones, J. E., Connell, A. M., Baron, J. H. and Jones, F. A. (1965). Controlled trial of sulphasalazine in maintenance therapy for ulcerative colitis. Lancet, 1, 185-188.

Moertel, C. G., and Bargen, J. A. (1959). A critical analysis of the use of salicylazosulphapyridine in chronic ulcerative colitis. Ann. intern. Med., 51, 879-889.

Peppercorn, M. A., and Goldman, P. (1972). The role of intestinal bacteria in the metabolism of salicylazosulphapyridine. $J$. Pharmacol. exp. Ther., 181, 555-562.

Sandberg, M., and Hansson, K. A. (1973). Determination of salicylazosulfapyridine in biological materials. Acta pharm. suec., 10, 107-110.

Schröder, H., and Campbell, D. E. S. (1972). Absorption metabolism and excretion of salicylazosulphapyridine in man. Clin. Pharmacol. Ther., 13, 539-551.

Svartz, N. (1942). Salazopyrin, a new sulfanilamide preparation. B. Therapeutic results in ulcerative colitis. Acta med. scand. 110, 580-581.

Svartz, N. (1948). The treatment of 124 cases of ulcerative colitis with salazopyrin and attempts of desensitization in cases of hypersensitivity to sulfa. Acta med. scand., Suppl., 206, 465-471.

Trier, E. (1948). Treatment of ulcerative colitis with phthalylsulphathiazole. Acta med. scand., 130. Suppl., 206, 473-479. 